\title{
WEEDS AND THE PASTURE COMMUNITY
}

\author{
P. J. Rumball and D. A. GRAnt \\ Grasslands Division, DSIR, Kaikohe and Palmerston North
}

\section{Summary}

Survey data on the spring pasture composition of lowland farms with better-than-average levels of animal production indicate that volunteer species make up about 20 to $60 \%$ of the herbage dry matter on offer, Reasons for this are suggested.

\section{INTRODUCTION}

A FARMER looking at all the uninvited plants in his pasture might aim a kick at a nearby thistle and go off to get the spray gear ready.

This illustrates one attitude to, and one technique for, dealing with weeds in the pasture.

This paper is not so concerned with what, when or how management techniques may be used to influence pasture composition, as with the reasons why these manipulations are necessary at all. Why is the pasture so variable and so changeable? What might the researcher and the farmer do to better encourage uniformity and stability in the pasture without sacrificing productivity?

The main aspects to be considered here are, first, the role of the pasture ecologist and the difficulties he faces in his efforts to determine the precise causes of invasion and, secondly, limitations in the practical situation. Finally, the question of whether the researcher and the farmer approaches can get closer together will be examined.

\section{RESEARCH}

The pasture community is rather more than $a$ collection of plants that happen to be growing together. But it is not the whole pasture ecosystem, which would include all the rest of the living organisms-both animal and plant-as well as the physical environment. The plant community is simply one of a number of levels of organizations that (like the other levels) has attributes that are unique to itself,

Much research has been carried out at the individual plant level - on plant physiology. Some idea has been gained of how 
growth and development of a plant are influenced by light, by temperature and by nutrients and water supply; why it grows quickly at some times of the year and not at others.

This knowledge is the basis for understanding at the next level - the species population. Here the reactions of the individual are multiplied many times, although the population has additional characteristics such as continuity and an evolving gene pool.

The next step up is the multi-population level where interrelationships between populations are studied and perhaps explained.

On the plant side, much of New Zealand's pastoral research effort has gone into these three levels: plant physiology, species selections, relationships of the dominant species with one another and with some selected environmental factors. Most recommendations reaching the farmer are extrapolations from this work.

Yet the farmer has a whole ecosystem to deal with. Instead of a few species and a few factors, there are many species and a great range of environmental variables. The complexity increases hugely. Since the resources needed to study at this level are correspondingly increased, research tails off, becomes less specific, and relies more and more on uncovering principles that will apply to many situations. Also it tries to focus on clearly identifiable problems which involve few variables and should produce straightforward answers.

To expand on this a little: the make-up of a pasture community varies in both space and time. The ecologist must also operate in a four-dimensional framework to analyse this variation. Then, to explain the causes of the patterns he finds, he needs to measure corresponding patterns in those environmental factors he considers most critical. Close correlations might be found but even so this constitutes only evidence, not proof, of a causal relationship.

The difficulties are illustrated by the study of Harris and Brougham (1968) in which the authors were accounting for weed invasion of a continuously grazed ryegrass/white clover sward.

Statistically significant negative associations were found between browntop and ryegrass and between browntop and Poa spp. Similarly, browntop was associated with lower soil nitrogen and with higher soil moisture. What are the causes and what are the effects? Does browntop invasion occur because ryegrass fails on areas of low nitrogen supply and it is a better competitor here than the poas? Does browntop prefer the areas of higher soil moisture or does it actually cause them? Correlations that are 
statistically significant are not necessarily biologically significant and vice versa.

In this example, variation in pasture composition was studied within a random area at a particular fixed time. It may be just as difficult to determine causes of variation when time is varied and the area fixed. Round-Turner (1970) analysed composition over a nine-year time span. A rising trend in clover, ryegrass and total production over the first three years was followed by a steady decline which corresponded with invasian of weed grasses. The author suggested that the decline was initiated by summer drought, but also stated that "the pattern of weed invasion . . . is extremely complex. It has not been possible to advance a convincing explanation for all the changes that have taken place,"

\section{PRACTICE}

Certified pasture varieties have necessarily been selected for high performance under favourable conditions. They have been given a wide genetic base to assist adaptation to the less favourable environments.

Environmental barriers to these varieties exist over much of the farming area, especially the hill and high country. These barriers are still being defined but they might consist of an unfavourable micro-climate, a moisture deficit, or more likely $\cdot a$ chronically low soil nutrient status, If all uncertified types were to be classified as weeds, then this area is, by definition, weedridden.

More relevant here is the composition of pastures on those farms with high animal production.

Survey data of this type are not readily available and what there are provide a broad guide rather than an accurate estimate.

The data in Fig, 1 are adapted from Palmer (1970) and O'Connor and Gregg (1971) and are in the form of per centile DM on offer at a single spring sampling.

Categories of composition are simply "sown species" made up of ryegrasses, cocksfoot and clovers, and "volunteer species" made up of the remainder.

The pastures sampled were at least three years old and were on dairy and sheep farms which in terms of animal output were better than average for the district. The 36 farms were located 


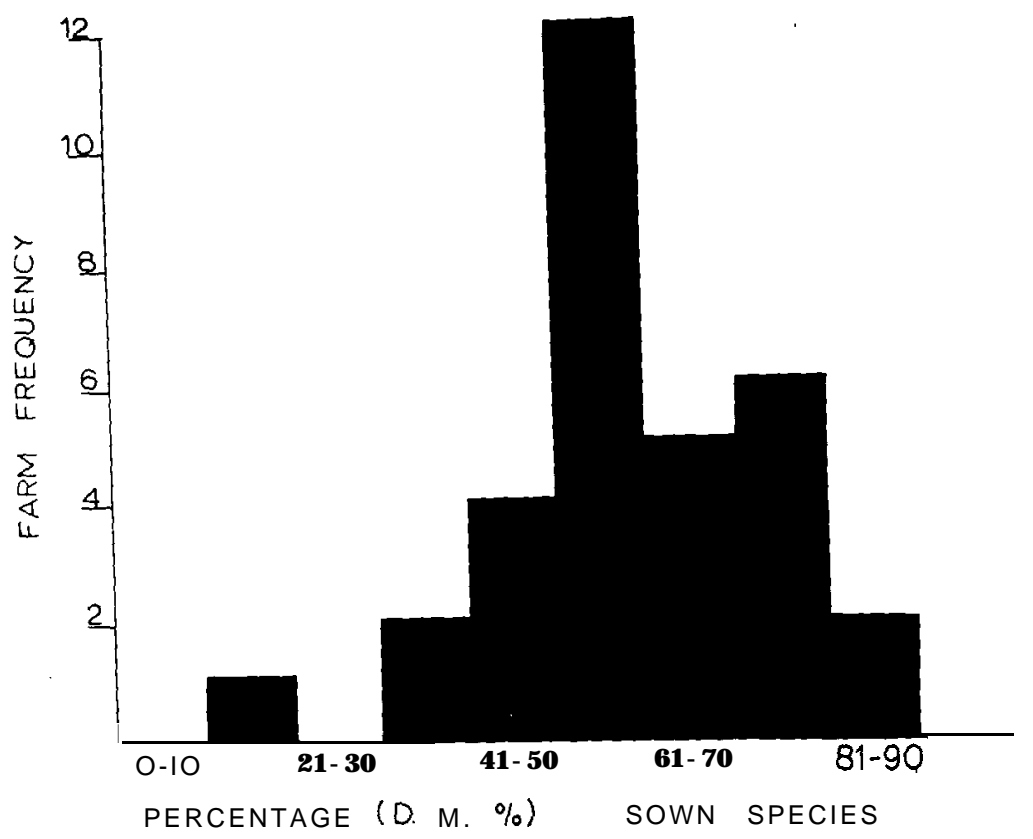

FIG. 1: Proportion of sown species in spring pasture. (Adapted from Palmer, 1970; 0 'Connor \& G regg, 1971).

in Northland, Waikato, Bay of Plenty, Taranaki, Manawatu, Wairarapa and Nelson.

Level of dominance of the sown species ranges between 11 to $20 \%$ and 81 to $90 \%$.

The range 41 to $80 \%$ includes five-sixths of the total farms and the mode of 51 to $60 \%$ includes more than one-third.

Such data do not indicate whether composition is poorer on the lower producing farms or whether animal output might be higher if composition tended towards a more "ideal" type. Correlations of pasture composition and animal production on either a regional or a national scale have yet to be published.

A farmer asking how to get a weed-free pasture is likely to be given a recipe involving seedbed preparation, seed mixtures and management practices to follow. From the animal adviser he learns that to maximize animal production he must go for high stocking rates and high utilization. There is a conflict here at the start. 
Periods of abnormal growth restriction, imposed for instance by drought or insect attack, are inevitable. Valuable management techniques have been developed to cushion the stress on the pasture community but, generally, during periods of feed shortage pasture is more expendable than the animal. Farmers may realize that the best way to eliminate Manawa ryegrass is to graze hard and often over summer or that to encourage dock entry is to stock heavily on wet soils during winter. The consequences of such mismanagements (from the pasture viewpoint) are predictable and well known and to patch up the damage there are such prescriptions as overdrilling and the use of selective herbicides.

The stresses most troublesome are those that may be very real but imperceptible. Without symptoms, the causes of weakening of the desirable plants can only be guessed at.

Except for Huia white clover, the certified varieties have limited ability for vegetative spread and gaps created by the loss of sown plants mean unexploited moisture and nutrients. These gaps will be filled by those plants that have the greatest opportunity and are best fitted for the particular niche that is left vacant.

Major scales of environmental variation, such as seepage areas or dry knobs, impose obvious patterns on composition but there are much more subtle variations where pattern may be hardly perceptible. The study of the nature and causes of plant distribution in space has shown just how dynamic and responsive the plant community is.

The fertility shift associated with animal behaviour can have a major effect on variation in the composition. Research into the barley grass problem has provided data on localized soil nutrient enrichment due to animal congregation. Excreta raises the levels of soluble cations, of salinity and of total nitrogen and phosphate (Grant and Ball, 1970; Metson et al., 1971). This animal-induced redistribution is intensifying problems on those soils where low phosphate is the clover-limiting factor.

Communities tend to evolve towards a stable composition and this generally implies an increasing diversity of species. The simple ryegrass/white clover association one tries to establish and maintain over a limitless range of environments is unlikely to be the most stable as well as the most productive. So far, no conscious efforts have been made to design a pasture community that is stable in composition as well as highly productive-no "easy care" pasture, in fact. 


\section{PROSPECT}

In their attempts to ensure a desirable type of pasture, research and practice come up against some quite definite obstacles. Where do we go from here?

Over recent years there has been an evolution in New Zealand's pastoral farming that could have significant repercussions on the design and management of pastures. This began with the swing to high inputs of fertilizers and stock on the dairy farms. Latterly, the energy demands of the dairy cow at different stages of production have been translated into practical language. It is being suggested that, in addition to his troublesome financial budget, the farmer should try his hand at a feed budget. The object is to allow the highly stocked farmer to optimize rationing during demand-supply squeezes yet still retain the very real advantages of in situ grazing.

The unit of this type of budget is the kilogram of dry matter. Estimates are made of feed units on hand, budgeted demand and hoped-for supply. With a surer basis for assessing how he is doing, the farmer should have more confidence to fix grazing patterns to get the best. out of his pastures as well as his stock. The empirical evidence already available suggests that rotation length and stocking density can influence pasture composition markedly.

These developments are likely to catch on in the intensive beef raising industry also, and in the sheep industry if the present efforts to boost fecundity are successful.

The trampling, grazing, voiding animal is one of the major determinants of pasture composition. The implication of these trends in feed rationing is that this major influence will come increasingly under control. This would seem to have considerable benefit for the researcher in that clearer definition of management would result in clearer definition of research objectives.

For the agronomist, there would be more scope to develop pasture types tailor-made for the environment and intended use in much the same way as crop plants are developed. There would be more definite dates of harvest and periods of recovery. The animal factor, being more amenable to control, could become an integral part of the research programme - unlike the present where there tends to be separation of plant and animal so that actual practice is an uneasy compromise.

For the plant ecologist, vacant niches in the community could be more easily identified and filled. On this theme, one of the 
consequences of intensified stocking has been a shift in make-up of the weed populations. In drier areas barley grass has expanded drastically (Rumball, 1970) and its counterpart in the moister parts is poa annua. In the northerly regions free-seeding or creeping summer-growing grasses are becoming a major pasture component (Matthews, 1971).

Thus, on highly stocked farms in both wet and dry areas, niches have opened up in the pasture community for quickestablishing, short-lived, cool- or warm-season-growing grasses able to utilize increased bare ground and spread into pasture as opportunity offers.

For the plant breeder, the specifications of his models could be better defined. Barclay (1959) stressed that real advances in plant breeding depend very much on precise definition of breeding objectives.

In general, researchers would be better able to tackle such aspects as resistance to stress and quicker recovery of the selected strains - by, for example, better protection of meristems, greater capacity for vegetative reproduction and spread, or re-establishment from seed within the sward. Subdominant plants or those with a restricted growth season might be fitted into the community to improve resilience.

For the farmer, treating the pasture more as a periodically harvested perennial crop seems to be a necessary management technique as stocking rate rises to high levels. From the pasture angle, he is better able to assess vigour by the speed of recovery and better able to influence composition and production. Higher inputs of fencing and labour should be increasingly offset by the trend towards streamlining or even automating the grazing system.

To conclude, a high quality, high yielding, low maintenance pasture is a necessary objective in grassland farming. Increasing grazing pressure tends to increase pasture stress and instability. To correct this, environmental variation - irrigation, drainage, etc. - which has a financial cost, can be smoothed out or the diversity of the pasture community, which is likely to have a yield cost, can be increased.

Further intensification of pastoral farming implies greater control of the harvest of pasture by the grazing animal, better definition of the pasture plants' grazing environment and more likelihood of designing a pasture community that is stable in composition as well as highly productive. 


\section{ACKNOWLEDGEMENTS}

Unpublished data o,n pasture composition were used by kind permission of P. B. Lynch, Director of Field Research Section, Department of Agriculture. Collection of data was by field research officers and were supplied by M. B. O'Connor.

\section{REFERENCES}

Barclay, P. C., 1959: Proc. N.Z. Grassld Ass., 21: 115-21.

Grant, D. A.: Ball, R. P., 1970: Proc. 23rd N.Z. Weed \& Pest Control Conf:: $83-9$

Harris, W.; Brougham, R. W., 1968: N.Z. $J l$ agric. Res., 11: 15-38.

Matthews, L. J., 1971: Proc. 24th N.Z. Weed \& Pest Control Conf.: 85-9. Metson, A. J.; Saunders, W. M. H.; Nott, J. H., 1971: N.Z. $J l$ agric. Res., 14: 33451 .

O’Connor, M. B.; Gregg, P. E. H., 1971: Proc. N.Z. Grassld Ass., 33: 26-34. Palmer, P. C., 1970: Proc. 23rd N.Z. Weed \& Pest Control Conf.: 51-6.

Round-Turner, N. L., 1970: Ibid.: 57-65.

Rumball, P. J., 1970: Ibid.: 70-82. 